\title{
Yale-NUS College sẽ đóng cửa vào 2025
}

- sciencevietnam

E Khoa học lý thú

(1) September 16, 2021

SSHPA (16-09-2021) - Ngày 26/8 vừa qua, Yale-NUS College, Singapore chính thức tuyên bố sẽ đóng cửa vào năm 2025, sau khi lứa học sinh cuối cùng của trường sẽ tốt nghiệp. Theo đó, trường mẹ National University of Singapore (NUS) sẽ sáp nhập chương trình University Scholars Programme (USP) và Yale-NUS College thành một trường mới trực thuộc NUS [1].

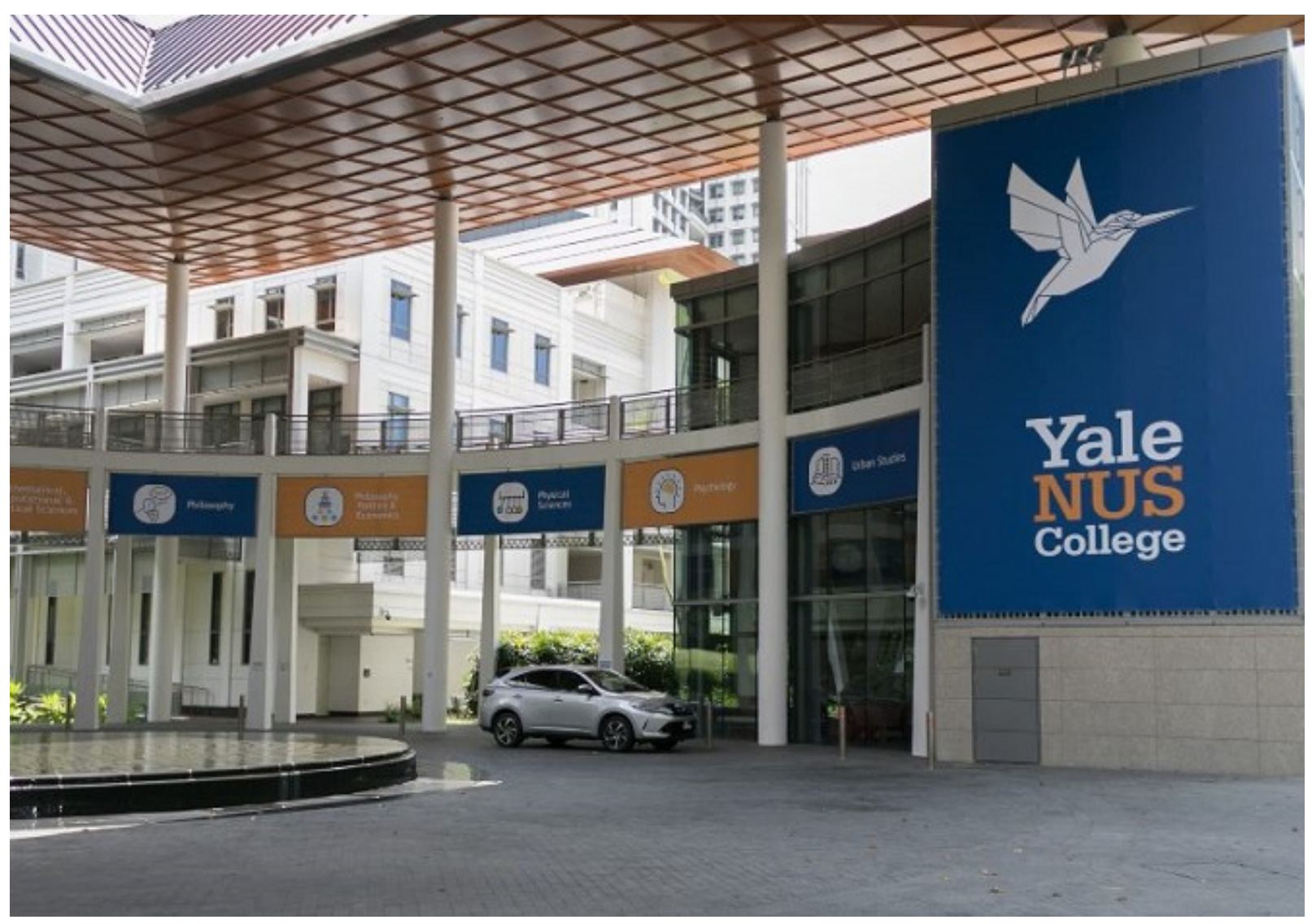

Được thành lập vào năm 2011 với sự đồng thuận của 2 tên tuổi lớn là Yale

University (Hoa Kỳ) và NUS, Yale-NUS College là một dự án giáo dục đặc biệt hướng tới sự kết hợp các giá trị tốt nhất của cả phương Tây và phương Đông. Theo Yahoo!News, phía Yale University không tham gia vào quá trình quản trị tại trường mới, và hợp tác hiện tại với Yale-NUS College cũng không hề có vấn đề gì xảy ra.

Trả lời rõ hơn về vấn đề này, Bộ trưởng Giáo dục Singapore Chan Chun Sing cho biết quyết định được đóng cửa là do các vấn đề nhạy cảm liên quan tới tài chính [2].

Trước các ảnh hưởng của đại dịch COVID-19, vấn đề chi phí đang khiến các cơ sơ giáo dục phải thay đổi cơ cấu [3]. Để theo học tại Yale-NUS College, một sinh viên phải chi trả chi phí gấp đôi một học sinh thông thường tại NUS. Mặc dù chấp nhận chi phí cao để mang lại các giá trị tốt nhất [4], nhưng khi đối diện với sự thật của các con số kế toán, lựa chọn thay đổi được đưa ra. 


\section{Tài liệu tham khảo:}

[1] Staff Writer, Singapore. (2021). Yale-NUS College to close in 2025; 2 new NUS colleges formed. Yahoo!News. URL: https://sg.news.yahoo.com/yale-nus-collegeclose-2025-2-new-nus-colleges-formed-043658190.html

[2] Nicholas Yong. (2021). Yale-NUS students, staff not consulted on closure due to 'sensitive' issues: Chan Chun Sing. Yahoo!News. URL: https://sg.news.yahoo.com /yale-nus-students-staff-not-consulted-closure-sensitive-issues-chan-chunsing-112310129.html

[3] SSHPA. (2021). Các trường ĐH Úc tái cơ cấu và cắt giảm nhân sự. SSHPA. URL: https://sc.sshpa.com/post/5727

[4] Vuong Quan Hoang. (2018). The (ir)rational consideration of the cost of science in transition economies. Nature Human Behaviour, 2(1), 5.

\section{(1) Last modified: 9/16/2021 5:50 PM $\quad$ O Views: 7 f 0 y 0}

\section{Bài liên quan:}

- Các trường ĐH Úc tái cơ cấu và cắt giảm nhân sự

- Học trực tuyến tại Việt Nam sau đại dịch COVID-19

- Năng lực nội tại KHXH\&NV Việt Nam giai đoạn 2008-2019

- Các nhà khoa học xã hội tăng cường nghiên cứu trong thời kì dịch bệnh

- Giáo dục trực tuyến: Cơ hội?

Ý kiến bạn đọc (0):

Comment

Gửi bình luận

(c) 2018 - 2021 EASE Vietnam SciComm System. All rights reserved. Powered by Vuong \& Associates. Built to serve the social sciences and humanities. 